Review Article

\title{
Cigarette Smoke-Induced Acquired Dysfunction of Cystic Fibrosis Transmembrane Conductance Regulator in the Pathogenesis of Chronic Obstructive Pulmonary Disease
}

\author{
Juan Shi, ${ }^{1,2}$ Hui Li, ${ }^{1,2,3}$ Chao Yuan, ${ }^{4}$ Meihui Luo, ${ }^{1,4}$ Jun Wei, ${ }^{1,2,3}$ and Xiaoming Liu $\mathbb{D}^{1,2,3,4}$ \\ ${ }^{1}$ College of Clinical Medicine, Ningxia Medical University, Yinchuan, Ningxia 750004, China \\ ${ }^{2}$ Ningxia Key Laboratory of Clinical and Pathological Microbiology, General Hospital of Ningxia Medical University, Yinchuan, \\ Ningxia 750004, China \\ ${ }^{3}$ Ningxia Institute for Stem Cell Research, General Hospital of Ningxia Medical University, Yinchuan, Ningxia 750004, China \\ ${ }^{4}$ College of Life Science, Ningxia University, Yinchuan, Ningxia 750021, China
}

Correspondence should be addressed to Xiaoming Liu; erc1080@163.com

Received 26 December 2017; Accepted 11 April 2018; Published 23 April 2018

Academic Editor: Kota V. Ramana

Copyright (C) 2018 Juan Shi et al. This is an open access article distributed under the Creative Commons Attribution License, which permits unrestricted use, distribution, and reproduction in any medium, provided the original work is properly cited.

\begin{abstract}
Chronic obstructive pulmonary disease (COPD) is a disease state characterized by airflow limitation that is not fully reversible. Cigarette smoke and oxidative stress are main etiological risks in COPD. Interestingly, recent studies suggest a considerable overlap between chronic bronchitis (CB) phenotypic COPD and cystic fibrosis (CF), a common fatal hereditary lung disease caused by genetic mutations of the cystic fibrosis transmembrane conductance regulator (CFTR) gene. Phenotypically, CF and COPD are associated with an impaired mucociliary clearance and mucus hypersecretion, although they are two distinct entities of unrelated origin. Mechanistically, the cigarette smoke-increased oxidative stress-induced CFTR dysfunction is implicated in COPD. This underscores CFTR in understanding and improving therapies for COPD by altering CFTR function with antioxidant agents and CFTR modulators as a great promising strategy for COPD treatments. Indeed, treatments that restore CFTR function, including mucolytic therapy, antioxidant ROS scavenger, CFTR stimulator (roflumilast), and CFTR potentiator (ivacaftor), have been tested in COPD. This review article is aimed at summarizing the molecular, cellular, and clinical evidence of oxidative stress, particularly the cigarette smoke-increased oxidative stress-impaired CFTR function, as well as signaling pathways of CFTR involved in the pathogenesis of COPD, with a highlight on the therapeutic potential of targeting CFTR for COPD treatment.
\end{abstract}

\section{Introduction}

Chronic obstructive pulmonary disease (COPD) is one of the most prevalent causes of mortality in the aging population worldwide, which is characterized by an irreversible chronic airflow limitation [1]. Emphysema and chronic bronchitis (CB) are two major clinical and epidemiological phenotypes of this chronic lung disease. Pathologically, inflammation in small airways (CB) and destruction of lung parenchyma (emphysema) are hallmarks of COPD. Of note, most patients with COPD exhibit symptoms of both $\mathrm{CB}$ and emphysema [2], although $\mathrm{CB}$ is typically the one predominant clinical phenotype in COPD patients [3]. Etiologically, cigarette smoke (CS) and the CS-caused oxidative stress are considered as the most common etiological factors in COPD. Clinically, a subgroup of patients with emphysema phenotype of COPD also develops CB accompanied by inflammatory airway wall thickening and/or bronchiectasis [4-6]. These manifestations support that the airway mucus obstruction may be a crucial factor in the pathogenesis of chronic inflammation driving disease progression in COPD $[7,8]$.

Cystic fibrosis $(\mathrm{CF})$ is a fatal heterogeneous recessive genetic disorder caused by mutations in the cystic fibrosis transmembrane conductance regulator (CFTR) gene, which 


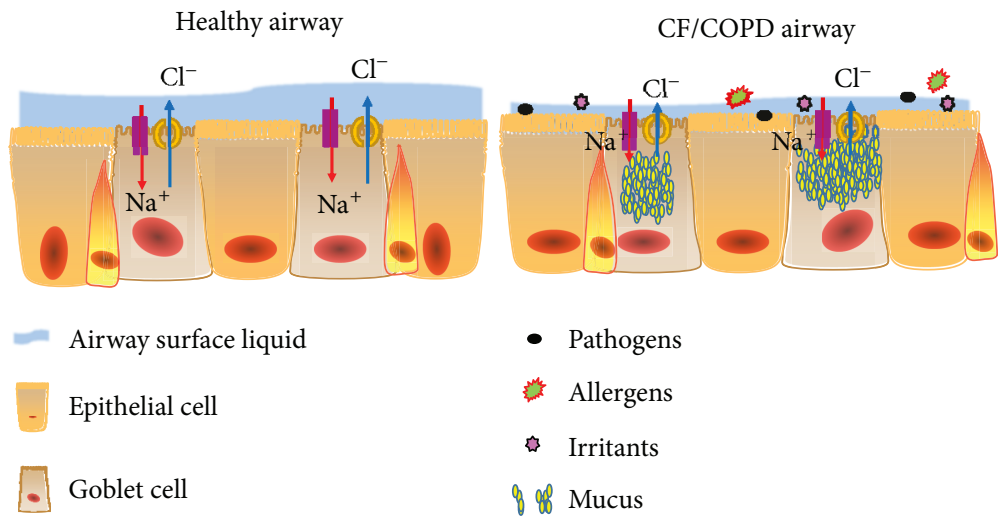

FIGURE 1: Model of airway surface dehydration (mucus hyperconcentration) in chronic obstructive pulmonary disease (COPD). The healthy airway surface (left panel) is covered with a thin film of mucus able to entrap inhaled insults that are constantly removed from the lungs by mucociliary clearance. The proper function of this innate airway defense mechanism largely relies on the function of CFTR, ENaC, and other alternative $\mathrm{Cl}^{-}$channels. In the COPD airway (right panel), the dysfunction of CFTR-mediated chloride channel leads net absorption of sodium leads to dehydration of airway surfaces, decreases ASL volume, and impairs mucus stasis and clearance.

is characterized by chronic bacterial infection in airways and sinuses, pancreatic exocrine insufficiency, and elevated concentrations of chloride in sweat [9]. Clinicopathologically, $\mathrm{CF}$ is a multiple organ disorder including airways and lung, pancreas, gastrointestinal tract, and reproductive organs. However, the disorder in airways and lung is considered as a primary cause of morbidity and is responsible for $85 \%$ of deaths in CF patients. It is therefore also a model of obstructive lung disease [10].

CFTR is an adenine nucleotide-binding cassette (ABC) protein and anion channel [11], which is responsible for the transportation of $\mathrm{Cl}^{-}$and $\mathrm{HCO}_{3}{ }^{-}$anions into the airway lumen, along with $\mathrm{Na}^{+}$and $\mathrm{H}_{2} \mathrm{O}$ following passively through the paracellular pathway, resulting in an isotonic increase in height/volume of airway surface liquid (ASL) [12]. Mutations in the CFTR gene lead to the dysfunction or deficiency of the CFTR protein, which in turn results in a decreased ASL volume and subsequent mucus dehydration/stasis, which in turn impair mucus clearance and the lung's innate defense $[13,14]$.

Interestingly, airway mucus obstruction is an important hallmark of both CF and COPD, particularly in the CB form of COPD. For example, the clinical manifestations of $\mathrm{CB}$ include sputum production and impaired mucus clearance with chronic inflammation, which are similar to clinical features in early CF lung disease [13]. Furthermore, studies on the $\mathrm{CB}$ phenotype of COPD have identified that the impaired mucociliary clearance (MCC) of airways is a critical pathological process that drives disease initiation and progression. Mechanistically, the efficiency of MCC is largely dependent on functions of CFTR and epithelial $\mathrm{Na}^{+}$channel (ENaC), ciliary beating, and appropriate rates of mucin secretion [15]. Even more importantly, the oxidative stress and toxic components of cigarette smoking (CS) are major causes of COPD, which can also lead to a decrease in the cellular levels of CFTR in airway epithelia [16]. Indeed, a compelling body of evidence supports the above findings; that is, the chronic CS exposure may induce the acquired CFTR dysfunction, subsequently contributing to the pathogenesis of CB [17-26]. Therefore, the pathophysiology of CF and COPD has been proposed to share a similar process of initiation and progression, including the decrease of the height/ volume of ASL and mucus dehydration/stasis/accumulation (Figure 1). Molecularly, the CFTR protein dysfunction is commonly seen in both disease conditions, except that the CFTR dysfunction is caused by genetic mutations in CF, while an acquired CFTR dysfunction caused by CS and oxidants is defined in the CB form of COPD [13]. These studies thus further highlight that lessons learned from CF may be applicable to COPD, suggesting that current therapeutic strategies in CF may be translated to COPD treatment, particularly in the $\mathrm{CB}$ phenotype of COPD. In this article, we summarize the implication of CFTR dysfunction that is induced by cigarette smoke exposure and oxidants in the development and progression of COPD, expound our current understanding of mechanisms of acquired CFTR dysfunction in the pathogenesis of COPD, and highlight the potential of recent breakthroughs in targeting CFTR in COPD treatment.

\section{Cigarette Smoke-Increased Oxidative Stress Impairs the Expression and Function of CFTR}

Although it has been well established that chronic cigarette smoke exposure is a principal etiological factor for COPD, mechanisms underpinning the pathogenesis of COPD remain largely unknown. Etiologically, a compelling body of evidence has demonstrated that cigarette smoke- (CS-) related oxidants and calcium conspire to impair the expression and function of CFTR in airway epithelia at various National Natural Science Foundation of Chinaextents, through a variety of molecular mechanisms at different levels, including the reduced expression of the CFTR transcript, diminished CFTR protein by accelerating protein degradation, and altered channel gating, subsequently leading to an acquired CFTR dysfunction $[13,16]$. In this regard, the CS 
showed an acute effect on airway ion transport and CFTR activity. The CFTR-mediated $\mathrm{Cl}^{-}$secretion could be significantly reduced following either an acute or a chronic cigarette smoke exposure in vitro and in vivo, resulting in a reduced channel gating, open probability, and mucus transport, as well as airway surface dehydration. Of interest, a chronic exposure of airway epithelial cells to cigarette smoke (CS) could lead to a $\sim 75 \%$ rapid decrease of the channel gating and open probability and an up to $60 \%$ inhibition of CFTR-mediated $\mathrm{Cl}^{-}$secretion in vivo (Figure 1) $[13,18-20$, 23]. Animal studies also experimentally demonstrated that the CS could reduce CFTR levels in lipid rafts, and the reduced CFTR level was involved in epithelial cell apoptosis and autophagy induced by CS [27].

Indeed, the above studies implied that acquired CFTR dysfunctions, along with the presence of CS-induced goblet cell metaplasia and mucin hypersecretion led to the failure of maintaining the proper mucus hydration of ASL in smokers, thus increasing the risk of mucus stasis and chronic airway diseases $[7,28]$. This notion was further supported by evidence that smokers with COPD exhibited a reduced CFTR-mediated $\mathrm{Cl}^{-}$secretion in the upper and lower airways, and such a deficient ion transport was correlated with airway mucus dehydration [20]. Of great interest, the CSinduced CFTR dysfunction was also found in extrapulmonary disorders that are characterized in $\mathrm{CF}$, such as pancreatitis, male infertility, and cachexia, suggesting that cigarette smoke could cause systemically impaired CFTR, probably via a circulating agent [22].

In addition, acrolein, ceramide, and cadmium are main three constituents of cigarette smoke metabolites, which have been implicated in CFTR dysfunctions in vitro and in vivo $[22-24,29]$. Among them, acrolein is a highly reactive cigarette smoke metabolite that forms covalent adducts with DNA and proteins [30] and is able to block CFTR by directly inhibiting channel gating [22]. As a major component of cigarette smoke, cadmium is also a prevalent environmental contaminant. Exposure to cadmium was found to inhibit the expression of the CFTR protein and subsequent chloride transport in human airway epithelial cells in vitro and human COPD lungs [31] and lungs of mice that were intranasally instilled with cadmium in vivo [32].

Similarly, more recent studies demonstrated that the smoke-induced accumulation of ceramide was associated with the inhibition of CFTR expression and the severity of emphysema in COPD patients, in whom the CS-induced ceramide accumulation mediated the pathogenesis of COPD through a mechanism by activating NF- $\kappa \mathrm{B}$ signaling and inducing epithelial cell apoptosis $[17,27,33]$. In order to explore how membrane CFTR modulated ceramide signaling in lung injury and emphysema, Bodas et al. evaluated CFTR in CFTR-deficient mice and COPD lung tissues [27, 33]. Their results revealed an inverse correlation between the expression of CFTR and severity of emphysema and ceramide accumulation in COPD patients compared with healthy subjects [33]. In addition, Pseudomonas aeruginosaLPS-induced lung injury could be much more effectively controlled by chemically inhibiting the de novo ceramide synthesis in CFTR wild-type mice relative to CFTR- deficient mice [27]. Further studies demonstrated that the CFTR-dependent lipid rafts and ceramide signaling played a modulatory role in CS-induced lung epithelial injury and emphysema, indicating that membrane CFTR was essential for regulating lipid raft ceramide accumulation and inflammatory signaling $[27,33]$. In addition to lung epithelial cells, CS could also alter CFTR lipid rafts in macrophages and impair macrophage bacterial phagocytosis and killing [34]. These studies clearly suggest that CS-induced acquired CFTR dysfunction contributes to the development and progression of COPD.

\section{Implications of CFTR in COPD Pathogenesis}

The CFTR-mediated chloride channel plays a pivotal role in vital cellular signaling processes contributing to cell homeostasis. A reduced or dysfunctional CFTR may lead to an impaired efflux of cell anions such as chloride and bicarbonate. A failure of anion transportation of epithelial cells may yield to an increased viscosity of secretions and mucus accumulation, impaired ASL homeostasis, reduced clearance of bacteria, and enhanced chronic infection and inflammation. Those ultimately promote the obstruction and fibrosis of epithelial tissues and organs, particularly of the lung [35]. Indeed, accumulating evidences have suggested the implication of CFTR dysfunction in the pathogenesis of COPD, which are listed in Table 1.

Owing to the similarities of several clinical manifestations between COPD and CF disease, the CFTR has been considered to be implicated in the pathogenesis of COPD. Genetically, the correlation between CFTR gene mutations and the risk of COPD was first examined. In this respect, a deletion of three nucleotides encoding phenylalanine at position 508 of the CFTR gene, delta F508 ( $\Delta$ F508), is the most common CF-causing mutation. The $\Delta \mathrm{F} 508$ mutation results in a $50 \%$ decrease in CFTR protein density and function in individuals carrying a heterozygous $\Delta \mathrm{F} 508$ mutation compared to those carrying a wild-type CFTR gene [40]. Intriguingly, human studies failed to determine an increased risk for COPD in carriers of the CFTR $\triangle$ F508 mutation [41, 42]. Moreover, the degree of reduction in CFTR protein function in $\triangle F 508$ heterozygous tracheal epithelial cells exposed to CS was not different from that in wild-type CFTR cells in vitro, although $\Delta \mathrm{F} 508$ carriers clinically exhibited a significant decrease in pulmonary functions of forced expiratory volume in one second (FEV1) and forced vital capacity (FVC) as compared with subjects bearing a non-CFTR mutation [43]. Unlike that seen in CFTR $\triangle$ F508 carriers, however, several early studies have identified an increased incidence of the CFTR R75Q and M470V mutation alleles in individuals with COPD $[36,44,45]$. In this regard, a 3.4-fold decrease in the risk of severe COPD was demonstrated in a Serbian population carrying the CFTR M470V variant genotype [46], while an increased risk of COPD was examined in subjects bearing a R75Q CFTR variation [45].

Of note, it has been well established that cigarette smoking-induced oxidative stress and/or inflammation can decrease CFTR activity and impair mucociliary transport in airway epithelial cells. But the presence of CFTR mutation 
TABLE 1: Studies on implications of CFTR in COPD.

\begin{tabular}{|c|c|c|c|c|}
\hline Object of study & Model & Molecular mechanism & Effect & Ref \\
\hline $\begin{array}{l}\text { Correlation of CFTR } \\
\text { mutations and COPD }\end{array}$ & $\begin{array}{c}\text { Subjects including } 20 \\
\text { patients with asthma, } \\
19 \text { with DB, and } 12 \text { with COPD }\end{array}$ & CFTR gene mutations & $\begin{array}{l}\text { The hyperactive M470 } \\
\text { allele was more frequent } \\
\text { in COPD patients }\end{array}$ & [36] \\
\hline $\begin{array}{l}\text { Impact of } \mathrm{ENaC} \text { on } \\
\text { CFTR function }\end{array}$ & $\begin{array}{c}\mathrm{C} 57 \mathrm{BL} / 6 \text { and } \mathrm{BALB} / \mathrm{c} \\
\text { mice overexpressing the } \\
\text { beta-ENaC subunit }\end{array}$ & $\begin{array}{l}\text { Overexpressing ENaC } \\
\text { impaired CFTR function }\end{array}$ & $\begin{array}{l}\text { Dysfunction of CFTR } \\
\text { contributed to the onset } \\
\text { and severity of COPD }\end{array}$ & [37] \\
\hline $\begin{array}{l}\text { Impact of cigarette } \\
\text { smoke on CFTR function }\end{array}$ & $\begin{array}{l}\text { Current and former smokers } \\
\text { with or without COPD }\end{array}$ & $\begin{array}{l}\text { Cigarette smoke induced } \\
\text { CFTR dysfunction and } \\
\text { correlated with COPD } \\
\text { disease phenotype }\end{array}$ & $\begin{array}{l}\text { Cigarette smoke induced } \\
\text { the acquired CFTR } \\
\text { dysfunction and contributes } \\
\text { to COPD pathogenesis }\end{array}$ & [20] \\
\hline $\begin{array}{l}\text { CFTR in COPD } \\
\text { pathogenesis }\end{array}$ & $\begin{array}{l}\text { GOLD 0/4 patients } \\
\text { and HBECs }\end{array}$ & $\begin{array}{l}\text { Cigarette smoke reduced } \\
\text { the expression of CFTR } \\
\text { protein and reduced airway } \\
\text { surface liquid height }\end{array}$ & $\begin{array}{l}\text { Cigarette smoke induced } \\
\text { CFTR dysfunction and } \\
\text { correlated with COPD } \\
\text { disease phenotype }\end{array}$ & [31] \\
\hline $\begin{array}{l}\mathrm{ENaC} \text { and CFTR } \\
\text { in COPD pathogenesis }\end{array}$ & $\begin{array}{l}\text { ATI cells and ATII cells } \\
\text { in distal lung tissues }\end{array}$ & $\begin{array}{l}\text { Augmentation of ENaC } \\
\text { induced CFTR dysfunction } \\
\text { and impaired lung function }\end{array}$ & $\begin{array}{c}\text { ENaC and CFTR-mediated } \\
\text { chloride channel are } \\
\text { biomarkers and potent } \\
\text { druggable targets of COPD }\end{array}$ & [38] \\
\hline $\begin{array}{l}\text { CFTR-mediated chloride } \\
\text { channel in COPD }\end{array}$ & $\begin{array}{l}\text { Healthy and COPD } \\
\text { smokers }\end{array}$ & $\begin{array}{l}\text { CFTR-mediated chloride } \\
\text { channel detected by } \\
\beta \text {-adrenergic sweat rate }\end{array}$ & $\begin{array}{l}\text { CFTR-mediated chloride } \\
\text { channel was significantly } \\
\text { reduced in COPD smokers } \\
\text { as detected by } \beta \text {-adrenergic } \\
\text { sweat rate, which was } \\
\text { associated with COPD } \\
\text { severity and clinical } \\
\text { symptoms of COPD }\end{array}$ & [39] \\
\hline $\begin{array}{l}\text { Cigarette smoke-impaired } \\
\text { CFTR function }\end{array}$ & $\begin{array}{l}\text { Cigarette smokers and } \\
\text { patients with COPD }\end{array}$ & $\begin{array}{l}\text { Cigarette smoke induced } \\
\text { CFTR dysfunction by } \\
\text { reducing CFTR mRNA, } \\
\text { accelerating degradation, } \\
\text { and altering channel gating }\end{array}$ & $\begin{array}{l}\text { Acquired CFTR induced } \\
\text { by cigarette smoke } \\
\text { contributed to COPD } \\
\text { with a clinical phenotype } \\
\text { similar to mild CF }\end{array}$ & [23] \\
\hline
\end{tabular}

ATI: alveolar type I; ATII: alveolar type II; COPD: chronic obstructive pulmonary disease; CFTR: cystic fibrosis transmembrane conductance regulator; DB: disseminated bronchiectasis; ENaC: epithelial sodium channel.

heterozygosity had no impact on the CS-induced reduction of CFTR activity, which did not increase the risk of COPD with CB either [43]. On the other hand, a reduced CFTR activity in the small airway was determined by transepithelial potential differences in smokers with or without COPD in comparison with healthy nonsmokers, and the difference was statistically significantly associated with symptoms of dyspnea and CB [20], although healthy cigarette smokers bearing no CFTR gene mutations also exhibited a marked decrease in CFTR function as determined by nasal potential difference (NPD) measurements [19]. These studies clearly imply that acquired CFTR dysfunctions induced by cigarette smoking may contribute to the pathophysiology of COPD. Indeed, this notion was further experimentally supported by several studies in murine models [37, 47]. For instance, mice overexpressing the beta subunit of $\mathrm{ENaC}(\beta$-ENaC) displayed a decreased CFTR function, along with an airway mucus obstruction and mortality, which were consistent with the role of CFTR in defining manifestations of the severity of COPD [37]. Furthermore, a sustained reduction of CFTR protein expression was found to correlate with the smoke-induced emphysema in mice with different genetic backgrounds (C57BL/6, ApoE2/2, A/J, CD1, and Nrf22/2) [47]. In humans, the abundance of CFTR protein in the lung tissue of patients with pulmonary emphysema was strikingly correlated with lung function (FEV1 and FVC) and inversely correlated with their COPD stages $[33,38]$.

Apart from the association of the loss of CFTR activity and manifestations in COPD lungs, a correlation between the dysfunction of systemic CFTR and abnormal gland secretion in skins has also been defined in COPD patients; that is, the $\beta$-adrenergic sweat rate was significantly reduced in COPD patients, which was associated with the severity and clinical symptoms of COPD [39, 48]. In addition, transcriptome meta-analysis using 13 independent microarray datasets from $\mathrm{CF}$; chronic pulmonary disorders, including COPD, IPF, and asthma; and environmental conditions, such as smoking and epithelial injury, recently identified that the CFTR gene was of potential therapeutic significance for these disorders [49]. This study also confirmed remarkable similarities in gene expression profiles between CF and COPD [49]. Taken together, these studies strongly support the hypothesis that acquired systemic CFTR dysfunctions induced by smoking play a causative role in COPD pathogenesis and contribute to the onset and severity of COPD, 
suggesting that CFTR may serve as a biomarker and potent druggable target for COPD treatment.

\section{Possible Mechanisms of Cigarette Smoke- Induced CFTR Dysfunction}

As mentioned in previous studies, CS could alter CFTR function by modulating the transcriptional expression of the gene, stability of the transcript, and stability and function of the protein [50]. In addition, numerous components, metabolites, and oxidants of CS were also able to modulate distinct CFTR functions at any steps of gene expression, stability, trafficking, and modification of CFTR protein $[13,16]$. Apart from CS, other environmental factors or developed agents, such as oxidative agents, are also able to modulate CFTR function in COPD (Table 2).

In this regard, both gaseous and soluble phases of CS are sources of oxidants, as CS can highly oxidize [58]. Of interest, oxidative stress is a well-known inhibitor of CFTR gene expression and trigger of inflammation (Figure 2) [59]. Vice versa, the impaired or defective CFTR is able to lead an increased production of reactive oxygen species (ROS) by activation of NADPH oxidase (NOX/DUOX) family members $[50,60]$. Therefore, oxidation alone has been suggested as one of the most important factors that had impacts on CFTR gene expression, protein density, and channel function $[50,60]$. Therefore, chronic exposure of lung cells to cigarette metabolites of oxidants was found to result in endoplasmic reticulum stress, unfolded protein response, accumulated ceramide, and increased cell apoptosis [50]. For instance, the defective CFTR encoded by $\triangle$ F508 gene mutation could induce oxidative inflammatory stress by ROS activation, which in turn induced autophagy impairment and accumulation of CFTR in aggresome bodies [17].

In addition to the above direct effects of oxidative stresses of CS and its metabolites, such as acrolein, ceramide, and cadmium on CFTR function, several other potential mechanisms have also been proposed to account for CFTR dysfunctions. One additional mechanism is that CS was able to impair CFTR trafficking by inducing protein internalization attributed by an acute misfolding of surface CFTR, which could rapidly clear CFTR from the plasma membrane [13, 61]. Intriguingly, the cigarette smoke-induced internalization of CFTR was not colocalized with lysosomal proteins but with the intermediate filament vimentin, indicating that the CFTR was trafficked into an aggresome-like perinuclear compartment of cells [13]. This was similar to that seen in cells expressing $\Delta$ F508 CFTR [17]. Mechanistically, the CS could induce $\mathrm{Ca}^{2+}$ release from lysosomes and increase cytoplasmic $\mathrm{Ca}^{2+}$ concentration, which in turn inhibits the normal route of CFTR sorting/degradation and reroutes CFTR internalization to aggresomes [16, 62]. This hypothesis was supported by an evidence that macrolide antibiotic bafilomycin A1 could inhibit the smoke-induced $\mathrm{Ca}^{2+}$ release and prevent CFTR internalization and clearance from the plasma membrane [62].

Together with the fact that chronic oxidative insults including CS, hypoxia, and chronic inflammation are the causes in the majority of COPD cases and oxidative stresses are able to impair CFTR function and are implicated in the pathogenesis of COPD, these studies suggest a common mechanism between COPD and CF disease (Figure 2). Therefore, a strategy restoring CFTR function may offer an opportunity for the treatment of COPD.

\section{CFTR as a Potential Therapeutic Target for COPD}

COPD has emerged as one of the most prevalent chronic diseases in the aging population and has become the fourth leading cause of death [63]. Unfortunately, there is no pharmacologic treatment currently available to alter the progressive decline in lung functions that ultimately leads to the disability and death of COPD patients [64]. Therefore, there is an ongoing unmet need to develop novel and effective agents for COPD treatments. Fortunately, owing to the overlap between COPD and CF in several key manifestations, including mucus hypersecretion, reduced mucociliary clearance, small airways' mucus obstruction, chronic bacterial infections and airway inflammation, and goblet cell metaplasia [65], together with the pathophysiological link of impaired CFTR function between these two chronic pulmonary diseases, therapeutic strategies for $\mathrm{CF}$ disease and pharmaceutical agents that target CFTR may therefore offer therapeutic effects in COPD patients.

Accordingly, this concept has motivated researchers to investigate CFTR dysfunction as a possible joint therapeutic target for CF, COPD, and other chronic airway diseases. There are indeed several therapeutic strategies, and approved and underdeveloped agents targeting CFTR channels have been attempted or translated into new treatments for mucus obstructive pulmonary diseases that share the same pathophysiology with CF, such as COPD, among which antioxidant ROS scavenger, mucus rehydration and mucolytic therapy, CFTR stimulator (phosphodiesterase (PDE) inhibitor), and CFTR potentiators gain the most interest in testing for COPD treatments (Figure 3).

Since the CB form of COPD is a disease at least in part related to CFTR dysfunction and mucus dehydration, the ASL/mucus rehydration may be thus beneficial in airway obstructive mucus clearance in COPD patients. Several strategies including osmotic agent-mediated direct rehydration, $\mathrm{ENaC}$ inhibition, and CFTR function restoration have been used for the increase of ASL volume/mucus rehydration $[13,66]$. For example, the aerosol delivery of hypertonic saline exhibited a promise by restoring rehydration, increasing ASL volume, improving mucus clearance and lung function, and accelerating mucociliary clearance (MCC) in CF and COPD patients, with an exception that the duration of action was relatively short in normal and COPD airways in comparison with CF airways $[13,66]$. Mechanistically, this scenario likely reflects the fact that the hypertonic saline results in a high salt concentration on airway surfaces, which in turn generates a gradient of $\mathrm{Cl}^{-}$to be absorbed through the partially functional CFTR-mediated channel and the paracellular pathway, together with the absorption of $\mathrm{Na}^{+}$by $\mathrm{ENaC}$ and the paracellular pathway, and these thus may limit the sustainability of osmotic effects on the surfaces of COPD 
TABLE 2: Impacts of cigarette smoke and other agents on CFTR function in COPD.

\begin{tabular}{|c|c|c|c|c|}
\hline Agents & Model & Molecular mechanism & Effect & Ref \\
\hline \multirow{3}{*}{ Cigarette smoke (CS) } & $\begin{array}{l}\text { Baby hamster kidney } \\
(\mathrm{BHK}) \text { cells }\end{array}$ & $\begin{array}{c}\text { CS induced CFTR } \\
\text { internalization and insolubility }\end{array}$ & $\begin{array}{l}\text { CS-induced CFTR dysfunction led to } \\
\text { airway surface liquid dehydration }\end{array}$ & {$[13]$} \\
\hline & $\begin{array}{c}\text { Endobronchial biopsy } \\
\text { specimens }\end{array}$ & $\begin{array}{l}\text { CS reduced lower airway CFTR } \\
\text { activity in COPD patients }\end{array}$ & $\begin{array}{l}\text { CS induced the acquired CFTR dysfunction } \\
\text { contributing to COPD pathogenesis }\end{array}$ & {$[20]$} \\
\hline & HBECs & Induced CFTR dysfunction & $\begin{array}{c}\mathrm{ENaC} \text { inhibition partially restored } \\
\text { CFTR function and mucus hydration } \\
\text { in } \mathrm{CB} \text { patients }\end{array}$ & {$[51]$} \\
\hline $\begin{array}{l}\text { Cigarette smoke } \\
\text { condensate (CSC) }\end{array}$ & $\begin{array}{l}\text { Primary MNSE } \\
\text { and HSNE }\end{array}$ & $\begin{array}{l}\text { CSC affects the calcium-activated } \\
\mathrm{Cl}^{-} \text {transport pathway }\end{array}$ & $\begin{array}{l}\text { CSC impaired CFTR functions in } \\
\text { epithelial cells }\end{array}$ & {$[52]$} \\
\hline $\begin{array}{l}\text { Cigarette smoke } \\
\text { extract (CSE) }\end{array}$ & Primary HBECs & $\begin{array}{l}\text { Cigarette smoking transmits } \\
\text { acute reductions in CFTR }\end{array}$ & $\begin{array}{l}\text { CFTR potentiator (VX-770) reversed } \\
\text { CFTR function }\end{array}$ & {$[23]$} \\
\hline $\begin{array}{l}\text { Tobacco carcinogen } \\
\text { NNK transporter MRP2 }\end{array}$ & Lung epithelial cells & $\begin{array}{l}\text { Induced dysfunction of CFTR, } \\
\text { MRP2, and PDZ proteins }\end{array}$ & $\begin{array}{l}\text { Contributed to cigarette } \\
\text { smoke-associated lung diseases, } \\
\text { such as COPD and lung cancer }\end{array}$ & {$[53]$} \\
\hline \multirow{3}{*}{ Roflumilast } & $\begin{array}{l}\text { Primary HBECs, } \\
\text { Calu-3, and T84 } \\
\text { monolayers }\end{array}$ & $\begin{array}{l}\text { Roflumilast activated } \\
\text { CFTR-mediated anion transport } \\
\text { in airway and intestinal epithelia } \\
\text { via a cAMP-dependent pathway }\end{array}$ & $\begin{array}{l}\text { Roflumilast partially reversed the } \\
\text { CS-impaired CFTR function and } \\
\text { resulted in augmented ASL depth }\end{array}$ & {$[40]$} \\
\hline & $\begin{array}{l}\text { Primary NHBE and } \\
\text { Vero cell VC-10 }\end{array}$ & $\begin{array}{l}\text { Roflumilast increased CFTR } \\
\text { mRNA levels in CS-exposed } \\
\text { cell cultures }\end{array}$ & $\begin{array}{c}\text { Roflumilast can rescue smoke-induced } \\
\text { mucociliary dysfunction by reversing } \\
\text { decreased CFTR activity }\end{array}$ & {$[54]$} \\
\hline & HBECs & $\begin{array}{l}\text { Roflumilast restored CFTR } \\
\text { function in CS-exposed cells }\end{array}$ & $\begin{array}{l}\text { Roflumilast combined with adenosine } \\
\text { increased mucosal hydration in } \\
\text { HBECs exposed to CS }\end{array}$ & {$[55]$} \\
\hline $\begin{array}{l}\text { 2-Cyano-3,12- } \\
\text { dioxooleana-1,9-dien- } \\
\text { 28-oic acid (CDDO) }\end{array}$ & Human lungs & $\begin{array}{l}\text { Chronic exposure of CS led to } \\
\text { endoplasmic reticulum stress, } \\
\text { unfolded CFTR protein } \\
\text { response, and cell apoptosis }\end{array}$ & $\begin{array}{l}\text { CDDO corrected defective } \\
\text { Nrf2-dependent cellular response } \\
\text { in chronic exposure of } \\
\text { CS-induced lung disease }\end{array}$ & {$[56]$} \\
\hline miR-101 and miR-144 & $\begin{array}{l}\text { HBECs and human } \\
\text { lung tissues }\end{array}$ & $\begin{array}{l}\text { Chronic exposure to CS } \\
\text { upregulated miR-101 and } \\
\text { miR-144, which suppressed } \\
\text { CFTR in COPD lungs }\end{array}$ & $\begin{array}{l}\text { miR-101 and miR-144 regulate } \\
\text { the expression of the CFTR } \\
\text { chloride channel in the lung }\end{array}$ & {$[57]$} \\
\hline Ivacaftor, VX-770 & Primary HBECs & $\begin{array}{l}\text { Cigarette smoking transmitted } \\
\text { acute reductions in CFTR activity } \\
\text { due to inhibition of } \\
\text { CFTR-dependent fluid transport }\end{array}$ & $\begin{array}{l}\text { Cigarette smoke-reduced mucus } \\
\text { transport in smokers could be } \\
\text { reversed by CFTR potentiator VX-770 }\end{array}$ & {$[23,25]$} \\
\hline Acrolein & $\begin{array}{l}\text { Primary HBECs and } \\
\text { A/J mice }\end{array}$ & $\begin{array}{l}\text { Acrolein blocked CFTR by } \\
\text { inhibiting channel gating }\end{array}$ & $\begin{array}{c}\text { Acrolein mediated systemic CFTR } \\
\text { dysfunction in smokers }\end{array}$ & {$[20]$} \\
\hline $\begin{array}{l}\text { Cadmium and } \\
\text { manganese }\end{array}$ & $\begin{array}{l}\text { 16HBE14o-cells and } \\
\text { human COPD lung } \\
\text { tissues }\end{array}$ & $\begin{array}{l}\text { Cadmium and manganese of CS } \\
\text { reduced levels of CFTR protein } \\
\text { and mRNA }\end{array}$ & $\begin{array}{l}\text { Accumulation of cadmium and } \\
\text { manganese reduced CFTR expression in } \\
\text { the lungs of patients with severe COPD }\end{array}$ & {$[31]$} \\
\hline $\begin{array}{l}\text { S-Nitrosoglutathione } \\
\text { (GSNO) }\end{array}$ & $\begin{array}{l}\text { The preclinical } \\
\text { COPD-emphysema } \\
\text { murine model }\end{array}$ & $\begin{array}{l}\text { Alleviated CS-induced acquired } \\
\text { CFTR dysfunction, resulting in } \\
\text { autophagy impairment }\end{array}$ & $\begin{array}{c}\text { Increasing GSNO levels reduced } \\
\text { CS-induced acquired CFTR } \\
\text { dysfunction and controlled COPD } \\
\text { emphysema pathogenesis }\end{array}$ & {$[17]$} \\
\hline
\end{tabular}

ASL: airway surface liquid; BHK: baby hamster kidney; CB: chronic bronchitis; CDDO: 2-cyano-3,12-dioxooleana-1,9-dien-28-oic acid; ENaC: epithelial sodium channel; CS: cigarette smoke; CSC: cigarette smoke condensate; CSE: cigarette smoke extract; GSNO: S-nitrosoglutathione; HBECs: human bronchial epithelial cultures; HSNE: human sinonasal epithelial; MNSE: primary murine nasal septal epithelial; MRP2: multidrug resistance protein-2; NNK: 4-(methylnitrosamino)-1-(3-pyridyl)-1-buta-none; NHBECs: normal human bronchial epithelial cells.

normal airways. Conversely, the fully defective CFTR function in CF airways completely loses the CFTR-mediated transcellular path for $\mathrm{Cl}^{-}$absorption, limiting the $\mathrm{Na}^{+}$ absorption and yielding the sustenance of the high concentration of $\mathrm{NaCl}$ on airway surfaces [13]. In addition, a preclinical study interrogating the hydration strategies in
COPD mouse model using hypertonic saline and preventive inhibition of the amiloride-sensitive epithelial $\mathrm{Na}^{+}$channel also demonstrated the effectiveness of hydration strategy in unplugging airway COPD, suggesting that hydration agents may be a promising therapeutic strategy to unplug mucus in the CB form of COPD [66], although currently such a 


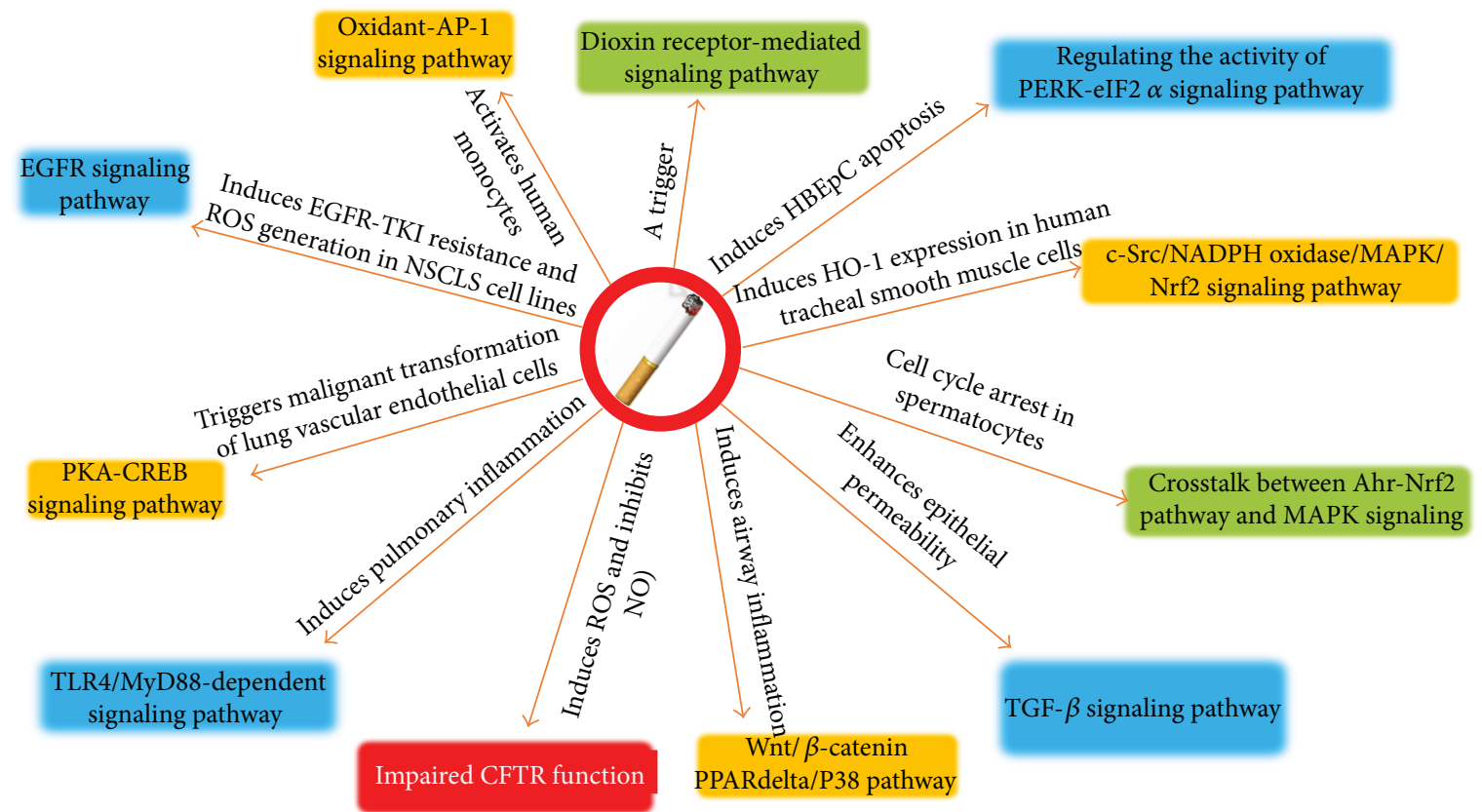

FIGURE 2: Signaling of oxidative stress activated by cigarette smoke. Cigarette smoke induces oxidative signaling and inflammatory responses. In this respect, cigarette smoke induces ROS production and impairs CFTR function, which is also a trigger of oxidative stress to activate the dioxin receptor-mediated signaling pathway and induce ROS production and cell cycle arrest or apoptosis and other signaling pathways.

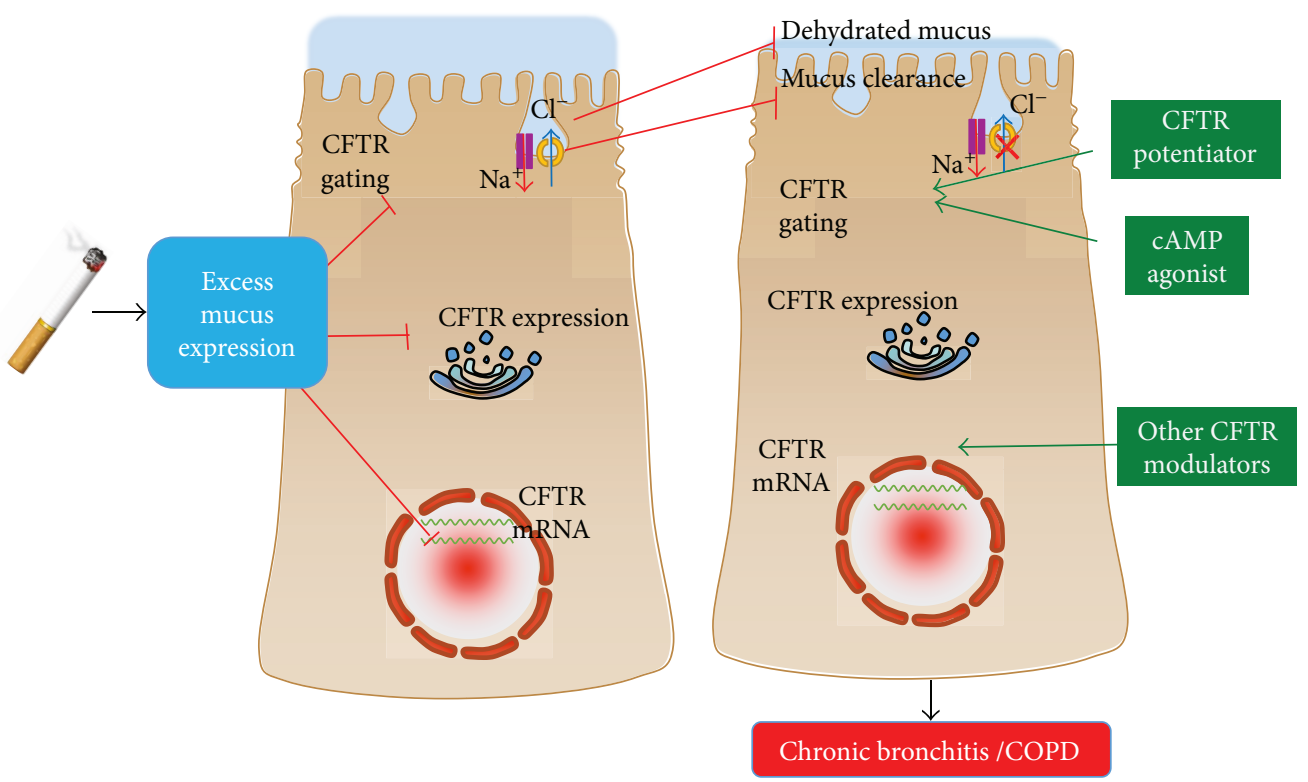

FIGURE 3: The cystic fibrosis transmembrane conductance regulator (CFTR) is a potential target for COPD treatment. The proper CFTR function is critical in maintaining the homeostasis of airway surface hydration and mucociliary clearance of normal airway epithelia. Cigarette smoke is able to induce excessive mucus secretion and has a negative impact on CFTR activation. The consequences of genetic and acquired CFTR dysfunction in patients with CB and COPD lead to a disreputable homeostasis of mucus and decreased ASL volume. The dehydrated mucus impairs the mucus clearance. Therefore, strategies that restore the CFTR function at different levels (mRNA and protein expression, stability, CFTR gating, and trafficking) using CFTR modulators (potentiator/corrector) and cAMP agonist (PDE inhibitors) may provide novel therapeutic approaches in obstructive pulmonary diseases, such as CB of COPD. The image on the left panel shows the cigarette smoke-induced CFTR dysfunction at different levels, and that in right the panel shows potential therapeutic interventions to restore CFTR function in cigarette smoke-exposed CFTR dysfunction. The red blocked line indicates an inhibition, and the green line with arrow represents an induction. 
mucolytic therapy only showed marginal benefits in COPD patients $[67,68]$.

CS is an important source of oxidative stress. Its induced intracellular ROS is a causative factor of COPD and a well-known CFTR inhibitor; therefore, several ROS scavengers have been expected to partially restore CFTR function and be used for COPD treatment. For instance, cysteamine is a reduced form of cystamine, which is an approved agent with antioxidant, antibacterial, and mucolytic properties. This agent has been shown to decrease lung inflammation and improve lung function in CF patients by potentially restoring autophagy and allowing CFTR to be trafficked to the cell membrane in a recent clinical trial $[17,69]$. In this context, accumulated polyubiquitinated proteins and impaired autophagy marker p62 of aggresome bodies were determined in cigarette smoke-exposed lung epithelial BEAS2 cells and murine lungs. In addition, increased aggresome bodies were also found in the lungs of smokers and COPD patients, which were correlated with the severity of emphysema and alveolar senescence, suggesting that cysteamine was capable of modulating the cigarette-induced pathogenesis of the emphysema phenotype of COPD by restoring impaired autophagy and CFTR function $[17,69,70]$.

Nitric oxide (NO) and S-nitrosoglutathione (GSNO), members of the S-nitrosothiol (SNO) group of bioactive NO reservoirs, play a crucial role in maintaining lung functional homeostasis under a physiological condition, in which intracellular levels of GSNO are controlled by the enzyme of S-nitrosoglutathione reductase (GSNOR) that degrades GSNO [71, 72]. Intriguingly, a recent study revealed low NO levels, along with an increased level of serum asymmetric dimethylarginine (ADMA) in COPD patients and current smokers, which was correlated with the severity of COPD, highlighting the importance of NO signaling in COPD emphysema pathogenesis [73, 74]. Equally noteworthy, a reduced GSNO level was determined in CF patients, consisting of the finding that GSNO played important roles in modulating the expression, maturation, and function of CFTR protein $[75,76]$. Therefore, increasing GSNO levels may be a promising strategy for treating obstructive lung disease, owing to the ability of GSNO to increase the maturation/ expression of CFTR by facilitating its rescue from aggresome bodies [71, 76]. Indeed, therapeutic benefits of augmentation of GSNO or treatment with GSNOR inhibitor (N6022) have been tested in several clinical trials.

A recent study on the effects and mechanism of GSNO augmentation in regulating inflammatory oxidative stress and COPD emphysema pathogenesis demonstrated that CFTR-colocalized aggresome bodies were correlated with an increasing emphysema severity in the lung of COPD subjects, and the treatment of GSNO or GSNOR inhibitor (N6022) could significantly inhibit cigarette smoke extract (CSE)-induced decrease of membrane CFTR, through a mechanism that involves rescuing CFTR from ubiquitin (Ub)-positive aggresome bodies and inhibiting CFTR protein misfolding. In addition, GSNO restoration could significantly inhibit CSE-induced ROS activation, chronic hypoxia(Ch-) CS-induced perinuclear CFTR protein accumulation, and autophagy impairment [17]. These studies thus suggested that increasing GSNO levels could prevent the pathogenesis of COPD emphysema by reducing CS-induced acquired CFTR dysfunction [17].

Since CFTR dysfunction can lead to a reduced responsiveness to the cyclic adenosine monophosphate (cAMP)/ protein kinase A (PKA) signaling pathway, pharmacological agents able to elevate intracellular cAMP have been used for the treatment of CF disease. In this context, phosphodiesterases (PDEs) can break down cAMP to regulate intracellular cAMP concentrations and diffusion; therefore, PDE inhibitors are able to inhibit cAMP breakdown and restore CFTR function. In this regard, selective PDE 4 and dual PDE3/4 inhibitors have anti-inflammatory and bifunctional bronchodilator effects in a preclinical study [77]. In this regard, the dual PDE3/4 inhibitor RPL554 has exhibited an ability to activate CFTR-dependent ion secretion in human primary bronchial epithelial cultures of CF patient carrying the R117H/F508del mutations [78]. To date, however, only one selective PDE4 inhibitor, the orally active roflumilast, has been licensed for the treatment of CB form of COPD [79].

Roflumilast was originally used for the treatment of inflammation in COPD. It could activate CFTR-dependent $\mathrm{Cl}^{-}$secretion by a cAMP-mediated pathway [40]. Since PDE4 is predominant in airway epithelial cells, roflumilast can induce or activate CFTR by increasing cAMP. Indeed, its ability to partially restore the CS-induced CFTR dysfunction in human bronchial epithelial cells (HBECs) [55] and increase CFTR mRNA levels in cell cultures exposed to cigarette smoke [54] has been shown. Such a roflumilast-restored CFTR-mediated chloride transport was further validated in CS-exposed mice [29]. In this study, A/J mice were exposed to CS or air for induction of CFTR dysfunction before they were treated with roflumilast. The NPD in vivo and shortcircuit current (Isc) analysis of trachea ex vivo were used for accessing CFTR-dependent chloride transport. Of note, the acute roflumilast treatment led to an increased CFTRdependent chloride transport in mice exposed to smoke or air. Moreover, the smoke-impaired CFTR function of mice could be completely reversed after oral administration of roflumilast for five weeks, further implicating the CFTR activation as a mechanism by which COPD patients with $\mathrm{CB}$ benefits from roflumilast treatment [29].

In addition to COPD treatments with PDE inhibitors by activating wild-type CFTR, a direct stimulation of CFTR activity with CFTR modulator may offer an alternative means to restore CFTR function in COPD $[26,80]$. In this respect, CFTR potentiators are a class of agents able to correct gating defects of mutant CFTR [81, 82]. Among them, ivacaftor (formerly VX-770) is a FDA-approved agent for the treatment of CF with 33 different CFTR mutations [23, 83]. Although CFTR potentiators were originally developed for restoring the function of mutant CFTR, some of them including ivacaftor were also able to enhance wild-type CFTR activity by augmenting open channel probability $[25,84]$. Indeed, human bronchial epithelial cells (HBECs) coexposed to ivacaftor and cigarette smoke extract (CSE) showed an increased CFTR-mediated $\mathrm{Cl}^{-}$secretion relative to cells exposed to CSE alone [23, 25]. 
Discouragingly, a recent pilot study evaluating ivacaftor treatment for 12 current or former smokers with COPD and $\mathrm{CB}$, however, reported that there was no significant improvement in CFTR function in patients receiving ivacaftor compared to those receiving placebo, as ascertained by improving sweat chloride concentrations and NPD [85]. In addition, a nonsignificant improvement in symptoms was observed in ivacaftor-treated patients either, as accessed by changes in the breathlessness, cough, and sputum scale (BCSS). Of interest, patients with the highest sweat chloride concentration at baseline also had the largest improvement in sweat chloride and BCSS, implying that patients with more severe CFTR dysfunction might benefit more from ivacaftor treatment at some extent by partially reversing CFTR function [85]. Conversely, chronic exposure of ivacaftor was found to inhibit wild-type CFTR by shortening the dwell time of CFTR in the plasma membrane, indicating that ivacaftor may not be the potentiator to reverse CFTR dysfunction in COPD patients [86]. However, improvements in CFTR activity and respiratory symptoms were observed in severe COPD patients receiving ivacaftor. This suggests that it is of importance to identify the most appropriate patient phenotypes involving differentiation based on the level of concomitant emphysema, bronchiectasis and disease severity, the status of smoking, and baseline CFTR function (and/or CFTR genotype) [24, 26].

\section{Conclusions}

Obstructive airway diseases, especially COPD, are common chronic diseases causing morbidity and mortality in the aging population worldwide. No pharmacotherapy is currently available for COPD; thus, there is an unmet need for novel and effective therapies to combat this disorder. Mechanistically, a compelling body of study has suggested that the acquired CFTR dysfunction induced by CS and its increased oxidative stress at least in part plays a pathogenic role in obstructive airway diseases other than the $\mathrm{CF}$, such as COPD, nonatopic asthma, and non-CF bronchiectasis. In this regard, even a small decrement in CFTR function may likely impose a striking effect on airway physiology and mucus clearance. In the case of COPD, CS-induced CFTR dysfunction and decrease of anion transport have largely been validated. In this context, toxic agents within CS are able to alter CFTR gene expression, protein stability, and anion conductance in healthy smokers and in COPD subjects, representing a novel target of CFTR for the development of therapeutic strategies. Therefore, targeting CFTR has recently spurred an increased interest in the treatment of CB phenotype of COPD [80].

Indeed, therapeutic strategies that reverse CFTR functions, including mucolytic therapy, antioxidant ROS scavenger, CFTR stimulator (PDE inhibitor), and CFTR potentiator, are under testing for COPD treatments (Figure 3). More importantly, several newly approved and developed CFTR modulators have offered a novel treatment opportunity for COPD. The introduction of both cAMP-dependent CFTR modulator (PDE inhibitor: roflumilast) and cAMP-independent CFTR modulator (CFTR potentiator: ivacaftor) has shown promise in potentiating CFTR function with increased CFTRmediated $\mathrm{Cl}^{-}$ion transportation in the treatment of acquired CFTR dysfunction in COPD. Particularly, the FDA's newly approved CFTR potentiator ivacaftor has been recently tested for safety and early efficacy in patients with the $\mathrm{CB}$ form of COPD. Together with the increasing evidence for therapeutic effects of CFTR restoration in COPD, it is reasonable to expand the investigation of CFTR modulators to this disorder.

In addition to roflumilast and ivacaftor, the next generation of potentiators targeting the CFTR gating defect in smoke-exposed human tissues and CFTR correctors (VX809, lumacaftor, and ABBV/GLPG-2222) restoring and/or enhancing CFTR trafficking to cell surface may provide novel strategies in COPD treatments [87]. Moreover, the combination of CFTR potentiator with CFTR corrector and/or PDE inhibitor may synergistically increase the effect of the restoration of CFTR function [78, 88]. For example, the CFTR potentiator VX-770 (ivacaftor) was found to further enhance dual PDE3/4 inhibitor RPL554-induced CFTR activity in primary HBECs [78]. Of note, the therapeutic strategies that restore CFTR function using PDE inhibitors and CFTR potentiators/correctors are relatively new; therefore, developing novel compounds or approaches to reverse CFTR dysfunction in cigarette smoke-exposed/CB airways may provide effective treatments for COPD.

\section{Abbreviations}

AAT: $\quad$ Alpha-1 antitrypsin

ABC: $\quad$ Adenine nucleotide-binding cassette

ADMA: Asymmetric dimethylarginine

ASL: $\quad$ Airway surface liquid

ATI: Alveolar epithelial type I

ATII: Alveolar epithelial type II

BCSS: Breathlessness, cough, and sputum scale

cAMP: Cyclic adenosine monophosphate

CB: $\quad$ Chronic bronchitis

CD: $\quad$ Methyl-beta-cyclodextran

CDDO: 2-Cyano-3,12-dioxooleana-1,9-dien-28-oic acid

CF: $\quad$ Cystic fibrosis

CFTR: Cystic fibrosis transmembrane conductance regulator

Ch: $\quad$ Chronic hypoxia

COPD: Chronic obstructive pulmonary disease

CS: $\quad$ Cigarette smoke

CSC: $\quad$ Cigarette smoke condensate

CSE: Cigarette smoke extract

DB: $\quad$ Disseminated bronchiectasis

AF508: Delta F508

DUOX: Dual oxidase

ENaC: $\quad$ Epithelial $\mathrm{Na}^{+}$channel

FEV1: $\quad$ Forced expiratory volume in one second

FHS/SHS: First-/second-hand cigarette smoke

FVC: $\quad$ Forced vital capacity

GOLD: Global Initiative for Chronic Obstructive Lung Disease

GSNO: S-Nitrosoglutathione

GSNOR: S-Nitrosoglutathione reductase 


$\begin{array}{ll}\text { HBECs: } & \text { Human bronchial epithelial cells } \\ \text { HSNE: } & \text { Human sinonasal epithelia } \\ \text { IPF: } & \text { Idiopathic pulmonary fibrosis } \\ \text { Isc: } & \text { Short-circuit current } \\ \text { MCC: } & \text { Mucociliary clearance } \\ \text { MNSE: } & \text { Primary murine nasal septal epithelia } \\ \text { MRP2: } & \text { Multidrug resistance protein-2 } \\ \text { NNK: } & \text { 4-(Methylnitrosamino)-1-(3-pyridyl)-1-buta- } \\ & \text { none } \\ \text { NO: } & \text { Nitric oxide } \\ \text { NOX: } & \text { NADPH oxidases } \\ \text { PDEs: } & \text { Phosphodiesterases } \\ \text { PKA: } & \text { Protein kinase A } \\ \text { RLMECs: } & \text { Primary rat lung microvascular cells } \\ \text { ROS: } & \text { Reactive oxygen species } \\ \text { S1P: } & \text { Transport of sphingosine-1 phosphate. }\end{array}$

\section{Conflicts of Interest}

The authors declare no conflict of interest.

\section{Authors' Contributions}

Juan Shi and Hui Li wrote the draft; Chao Yuan, Meihui Luo, and Jun Wei collected the references, prepared the tables, and drew the figures; and Juan Shi, Hui Li, and Xiaoming Liu critically revised the manuscript. All authors read and approved the final version of the manuscript. Juan Shi and Hui Li contributed equally to this work.

\section{Acknowledgments}

This work was supported by grants from the National Natural Science Foundation of China (Grant nos. 31472191 and 81460247).

\section{References}

[1] R. Marçôa, D. M. Rodrigues, M. Dias et al., "Classification of chronic obstructive pulmonary disease (COPD) according to the new Global Initiative for Chronic Obstructive Lung Disease (GOLD) 2017: comparison with GOLD 2011," COPD: Journal of Chronic Obstructive Pulmonary Disease, vol. 15, no. 1, pp. 21-26, 2018.

[2] V. Kim and G. J. Criner, "Chronic bronchitis and chronic obstructive pulmonary disease," American Journal of Respiratory and Critical Care Medicine, vol. 187, no. 3, pp. 228-237, 2013.

[3] J. C. Hogg, F. Chu, S. Utokaparch et al., "The nature of smallairway obstruction in chronic obstructive pulmonary disease," New England Journal of Medicine, vol. 350, no. 26, pp. 26452653, 2004.

[4] S. Lonni, J. D. Chalmers, P. C. Goeminne et al., "Etiology of non-cystic fibrosis bronchiectasis in adults and its correlation to disease severity," Annals of the American Thoracic Society, vol. 12, no. 12, pp. 1764-1770, 2015.

[5] J. R. Hurst, J. Stuart Elborn, and A. De Soyza, "COPD-bronchiectasis overlap syndrome," European Respiratory Journal, vol. 45 , no. 2, pp. 310-313, 2015.
[6] D. A. Lynch, J. H. M. Austin, J. C. Hogg et al., "CT-definable subtypes of chronic obstructive pulmonary disease: a statement of the Fleischner Society," Radiology, vol. 277, no. 1, pp. 192-205, 2015.

[7] J. V. Fahy and B. F. Dickey, "Airway mucus function and dysfunction," New England Journal of Medicine, vol. 363, no. 23, pp. 2233-2247, 2010.

[8] M. A. Sze, P. A. Dimitriu, M. Suzuki et al., "Host response to the lung microbiome in chronic obstructive pulmonary disease," American Journal of Respiratory and Critical Care Medicine, vol. 192, no. 4, pp. 438-445, 2015.

[9] B. H. Rosen, M. Chanson, L. R. Gawenis et al., "Animal and model systems for studying cystic fibrosis," Journal of Cystic Fibrosis, vol. 17, no. 2, pp. S28-S34, 2018.

[10] L. M. Filkins and G. A. O’Toole, "Cystic fibrosis lung infections: polymicrobial, complex, and hard to treat," PLoS Pathogens, vol. 11, no. 12, article e1005258, 2015.

[11] J. R. Riordan, "Assembly of functional CFTR chloride channels," Annual Review of Physiology, vol. 67, no. 1, pp. 701718, 2005.

[12] C. A. Hobbs, C. Da Tan, and R. Tarran, "Does epithelial sodium channel hyperactivity contribute to cystic fibrosis lung disease?," Journal of Physiology, vol. 591, no. 18, pp. 43774387, 2013.

[13] L. A. Clunes, C. M. Davies, R. D. Coakley et al., "Cigarette smoke exposure induces CFTR internalization and insolubility, leading to airway surface liquid dehydration," FASEB Journal, vol. 26, no. 2, pp. 533-545, 2012.

[14] J. F. Collawn and S. Matalon, "CFTR and lung homeostasis," American Journal of Physiology. Lung Cellular and Molecular Physiology, vol. 307, no. 12, pp. L917-L923, 2014.

[15] A. Ghosh, R. C. Boucher, and R. Tarran, "Airway hydration and COPD," Cellular and Molecular Life Sciences, vol. 72, no. 19, pp. 3637-3652, 2015.

[16] A. P. Braun, "Cigarette smoke and calcium conspire to impair CFTR function in airway epithelia," Channels, vol. 8, no. 3, pp. 172-173, 2014.

[17] M. Bodas, D. Silverberg, K. Walworth, K. Brucia, and N. Vij, "Augmentation of S-nitrosoglutathione controls cigarette smoke-induced inflammatory-oxidative stress and chronic obstructive pulmonary disease-emphysema pathogenesis by restoring cystic fibrosis transmembrane conductance regulator function," Antioxidants \& Redox Signaling, vol. 27, no. 7, pp. 433-451, 2017.

[18] A. M. Cantin, "Cystic fibrosis transmembrane conductance regulator: implications in cystic fibrosis and chronic obstructive pulmonary disease," Annals of the American Thoracic Society, vol. 13, Supplement 2, pp. S150-S155, 2016.

[19] A. M. Cantin, J. W. Hanrahan, G. Bilodeau et al., "Cystic fibrosis transmembrane conductance regulator function is suppressed in cigarette smokers," American Journal of Respiratory and Critical Care Medicine, vol. 173, no. 10, pp. 11391144, 2006.

[20] M. T. Dransfield, A. M. Wilhelm, B. Flanagan et al., "Acquired cystic fibrosis transmembrane conductance regulator dysfunction in the lower airways in COPD," Chest, vol. 144, no. 2, pp. 498-506, 2013.

[21] A. Rab, S. M. Rowe, S. V. Raju, Z. Bebok, S. Matalon, and J. F. Collawn, "Cigarette smoke and CFTR: implications in the pathogenesis of COPD," American Journal of Physiology. Lung 
Cellular and Molecular Physiology, vol. 305, no. 8, pp. L530L541, 2013.

[22] S. V. Raju, P. L. Jackson, C. A. Courville et al., "Cigarette smoke induces systemic defects in cystic fibrosis transmembrane conductance regulator function," American Journal of Respiratory and Critical Care Medicine, vol. 188, no. 11, pp. 1321-1330, 2013.

[23] S. V. Raju, V. Y. Lin, L. Liu et al., "The cystic fibrosis transmembrane conductance regulator potentiator ivacaftor augments mucociliary clearance abrogating cystic fibrosis transmembrane conductance regulator inhibition by cigarette smoke," American Journal of Respiratory Cell and Molecular Biology, vol. 56, no. 1, pp. 99-108, 2017.

[24] S. V. Raju, G. M. Solomon, M. T. Dransfield, and S. M. Rowe, "Acquired cystic fibrosis transmembrane conductance regulator dysfunction in chronic bronchitis and other diseases of mucus clearance," Clinics in Chest Medicine, vol. 37, no. 1, pp. 147-158, 2016.

[25] P. A. Sloane, S. Shastry, A. Wilhelm et al., "A pharmacologic approach to acquired cystic fibrosis transmembrane conductance regulator dysfunction in smoking related lung disease," PLoS One, vol. 7, no. 6, article e39809, 2012.

[26] G. M. Solomon, S. V. Raju, M. T. Dransfield, and S. M. Rowe, "Therapeutic approaches to acquired cystic fibrosis transmembrane conductance regulator dysfunction in chronic bronchitis," Annals of the American Thoracic Society, vol. 13, Supplement 2, pp. S169-S176, 2016.

[27] M. Bodas, T. Min, and N. Vij, "Critical role of CFTR-dependent lipid rafts in cigarette smoke-induced lung epithelial injury," American Journal of Physiology. Lung Cellular and Molecular Physiology, vol. 300, no. 6, pp. L811-L820, 2011.

[28] B. Button, L. H. Cai, C. Ehre et al., "A periciliary brush promotes the lung health by separating the mucus layer from airway epithelia," Science, vol. 337, no. 6097, pp. 937-941, 2012.

[29] S. V. Raju, L. Rasmussen, P. A. Sloane, L. P. Tang, E. F. Libby, and S. M. Rowe, "Roflumilast reverses CFTR-mediated ion transport dysfunction in cigarette smoke-exposed mice," Respiratory Research, vol. 18, no. 1, p. 173, 2017.

[30] J. F. Stevens and C. S. Maier, “Acrolein: sources, metabolism, and biomolecular interactions relevant to human health and disease," Molecular Nutrition \& Food Research, vol. 52, no. 1, pp. 7-25, 2008.

[31] F. Hassan, X. Xu, G. Nuovo et al., "Accumulation of metals in GOLD4 COPD lungs is associated with decreased CFTR levels," Respiratory Research, vol. 15, no. 1, p. 69, 2014.

[32] J. Rennolds, S. Butler, K. Maloney et al., "Cadmium regulates the expression of the CFTR chloride channel in human airway epithelial cells," Toxicological Sciences, vol. 116, no. 1, pp. 349358, 2010.

[33] M. Bodas, T. Min, S. Mazur, and N. Vij, "Critical modifier role of membrane-cystic fibrosis transmembrane conductance regulator-dependent ceramide signaling in lung injury and emphysema," Journal of Immunology, vol. 186, no. 1, pp. 602-613, 2011.

[34] I. Ni, C. Ji, and N. Vij, "Second-hand cigarette smoke impairs bacterial phagocytosis in macrophages by modulating CFTR dependent lipid-rafts," PLoS One, vol. 10, no. 3, article e0121200, 2015.

[35] F. Becq, "On the discovery and development of CFTR chloride channel activators," Current Pharmaceutical Design, vol. 12, no. 4, pp. 471-484, 2006.
[36] M. Tzetis, A. Efthymiadou, S. Strofalis et al., "CFTR gene mutations-including three novel nucleotide substitutions-and haplotype background in patients with asthma, disseminated bronchiectasis and chronic obstructive pulmonary disease," Human Genetics, vol. 108, no. 3, pp. 216-221, 2001.

[37] B. Johannesson, S. Hirtz, J. Schatterny, C. Schultz, and M. A. Mall, "CFTR regulates early pathogenesis of chronic obstructive lung disease in $\beta \mathrm{ENaC}$-overexpressing mice," PLoS One, vol. 7, no. 8, article e44059, 2012.

[38] R. Zhao, X. Liang, M. Zhao et al., "Correlation of apical fluidregulating channel proteins with lung function in human COPD lungs," PLoS One, vol. 9, no. 10, article e109725, 2014.

[39] C. A. Courville, S. Tidwell, B. Liu, F. J. Accurso, M. T. Dransfield, and S. M. Rowe, "Acquired defects in CFTRdependent $\beta$-adrenergic sweat secretion in chronic obstructive pulmonary disease," Respiratory Research, vol. 15, no. 1, p. 25, 2014.

[40] J. A. Lambert, S. V. Raju, L. P. Tang et al., "Cystic fibrosis transmembrane conductance regulator activation by roflumilast contributes to therapeutic benefit in chronic bronchitis," American Journal of Respiratory Cell and Molecular Biology, vol. 50, no. 3, pp. 549-558, 2014.

[41] M. Dahl, "Genetic and biochemical markers of obstructive lung disease in the general population," Clinical Respiratory Journal, vol. 3, no. 2, pp. 121-122, 2009.

[42] A. Artlich, A. Boysen, S. Bunge, P. Entzian, M. Schlaak, and E. Schwinger, "Common CFTR mutations are not likely to predispose to chronic bronchitis in northern Germany," Human Genetics, vol. 95, no. 2, pp. 226-228, 1995.

[43] S. Raju, J. H. Tate, S. K. G. Peacock et al., "Impact of heterozygote CFTR mutations in COPD patients with chronic bronchitis," Respiratory Research, vol. 15, no. 1, p. 18, 2014.

[44] S. Akai, H. Okayama, S. Shimura, Y. Tanno, H. Sasaki, and T. Takishima, "Delta F508 mutation of cystic fibrosis gene is not found in chronic bronchitis with severe obstruction in Japan," American Review of Respiratory Disease, vol. 146, no. 3, pp. 781-783, 1992.

[45] A. Divac, A. Nikolic, M. Mitic-Milikic et al., "High frequency of the R75Q CFTR variation in patients with chronic obstructive pulmonary disease," Journal of Cystic Fibrosis, vol. 3, no. 3, pp. 189-191, 2004.

[46] M. Stankovic, A. Nikolic, A. Divac et al., "The CFTR M470V gene variant as a potential modifier of COPD severity: study of Serbian population," Genetic Testing, vol. 12, no. 3, pp. 357-362, 2008.

[47] M. Cabanski, B. Fields, S. Boue et al., "Transcriptional profiling and targeted proteomics reveals common molecular changes associated with cigarette smoke-induced lung emphysema development in five susceptible mouse strains," Inflammation Research, vol. 64, no. 7, pp. 471-486, 2015.

[48] C. A. Courville, S. V. Raju, B. Liu, F. J. Accurso, M. T. Dransfield, and S. M. Rowe, "Recovery of acquired cystic fibrosis transmembrane conductance regulator dysfunction after smoking cessation," American Journal of Respiratory and Critical Care Medicine, vol. 192, no. 12, pp. 15211524, 2015.

[49] L. A. Clarke, H. M. Botelho, L. Sousa, A. O. Falcao, and M. D. Amaral, "Transcriptome meta-analysis reveals common differential and global gene expression profiles in cystic fibrosis and other respiratory disorders and identifies CFTR regulators," Genomics, vol. 106, no. 5, pp. 268-277, 2015. 
[50] N. Pongnimitprasert, J. El-Benna, M. J. Foglietti, M. A. Gougerot-Pocidalo, M. Bernard, and F. Braut-Boucher, "Potential role of the "NADPH oxidases" (NOX/DUOX) family in cystic fibrosis," Annales De Biologie Clinique, vol. 66, no. 6, pp. 621-629, 2008.

[51] A. B. M. Åstrand, M. Hemmerling, J. Root et al., "Linking increased airway hydration, ciliary beating, and mucociliary clearance through ENaC inhibition," American Journal of Physiology. Lung Cellular and Molecular Physiology, vol. 308, no. 1, pp. L22-L32, 2015.

[52] F. W. Virgin, C. Azbell, D. Schuster et al., "Exposure to cigarette smoke condensate reduces calcium activated chloride channel transport in primary sinonasal epithelial cultures," Laryngoscope, vol. 120, no. 7, pp. 1465-1469, 2010.

[53] C. Norez, C. Jayle, F. Becq, and C. Vandebrouck, "Bronchorelaxation of the human bronchi by CFTR activators," Pulmonary Pharmacology \& Therapeutics, vol. 27, no. 1, pp. 38-43, 2014.

[54] A. Schmid, N. Baumlin, P. Ivonnet et al., "Roflumilast partially reverses smoke-induced mucociliary dysfunction," Respiratory Research, vol. 16, no. 1, p. 135, 2015.

[55] J. Tyrrell, X. Qian, J. Freire, and R. Tarran, "Roflumilast combined with adenosine increases mucosal hydration in human airway epithelial cultures after cigarette smoke exposure," American Journal of Physiology. Lung Cellular and Molecular Physiology, vol. 308, no. 10, pp. L1068-L1077, 2015.

[56] A. M. Cantin, "Cellular response to cigarette smoke and oxidants: adapting to survive," Proceedings of the American Thoracic Society, vol. 7, no. 6, pp. 368-375, 2010.

[57] F. Hassan, G. J. Nuovo, M. Crawford et al., "MiR-101 and miR144 regulate the expression of the CFTR chloride channel in the lung," PLoS One, vol. 7, no. 11, article e50837, 2012.

[58] W. A. Pryor, D. G. Prier, and D. F. Church, "Electron-spin resonance study of mainstream and sidestream cigarette smoke: nature of the free radicals in gas-phase smoke and in cigarette tar," Environmental Health Perspectives, vol. 47, pp. 345-355, 1983.

[59] A. M. Cantin, G. Bilodeau, C. Ouellet, J. Liao, and J. W. Hanrahan, "Oxidant stress suppresses CFTR expression," American Journal of Physiology Cell Physiology, vol. 290, no. 1, pp. C262-C270, 2006.

[60] S. E. Cheng, I. T. Lee, C. C. Lin, Y. R. Kou, and C. M. Yang, "Cigarette smoke particle-phase extract induces HO-1 expression in human tracheal smooth muscle cells: role of the c-Src/ NADPH oxidase/MAPK/Nrf2 signaling pathway," Free Radical Biology \& Medicine, vol. 48, no. 10, pp. 1410-1422, 2010.

[61] J. M. Younger, L. Chen, H. Y. Ren et al., "Sequential quality-control checkpoints triage misfolded cystic fibrosis transmembrane conductance regulator," Cell, vol. 126, no. 3, pp. 571-582, 2006.

[62] J. E. Rasmussen, J. T. Sheridan, W. Polk, C. M. Davies, and R. Tarran, "Cigarette smoke-induced $\mathrm{Ca}^{2+}$ release leads to cystic fibrosis transmembrane conductance regulator (CFTR) dysfunction," Journal of Biological Chemistry, vol. 289, no. 11, pp. 7671-7681, 2014.

[63] R. A. Pauwels, A. S. Buist, P. M. Calverley, C. R. Jenkins, S. S. Hurd, and GOLD Scientific Committee, "Global strategy for the diagnosis, management, and prevention of chronic obstructive pulmonary disease. NHLBI/WHO Global Initiative for Chronic Obstructive Lung Disease (GOLD) Workshop summary," American Journal of Respiratory and Critical Care Medicine, vol. 163, no. 5, pp. 1256-1276, 2001.
[64] J. Vestbo, S. S. Hurd, A. G. Agustí et al., “Global strategy for the diagnosis, management, and prevention of chronic obstructive pulmonary disease: GOLD executive summary," American Journal of Respiratory and Critical Care Medicine, vol. 187, no. 4, pp. 347-365, 2013.

[65] K. Berg and J. L. Wright, "The pathology of chronic obstructive pulmonary disease: progress in the 20th and 21st centuries," Archives of Pathology \& Laboratory Medicine, vol. 140, no. 12, pp. 1423-1428, 2016.

[66] M. A. Mall, "Unplugging mucus in cystic fibrosis and chronic obstructive pulmonary disease," Annals of the American Thoracic Society, vol. 13, Supplement 2, pp. S177-S185, 2016.

[67] J. P. Zheng, J. Kang, S. G. Huang et al., "Effect of carbocisteine on acute exacerbation of chronic obstructive pulmonary disease (PEACE Study): a randomised placebo-controlled study," Lancet, vol. 371, no. 9629, pp. 2013-2018, 2008.

[68] M. Decramer, M. R.-v. Mölken, P. N. Richard Dekhuijzen et al., "Effects of $\mathrm{N}$-acetylcysteine on outcomes in chronic obstructive pulmonary disease (Bronchitis Randomized on NAC CostUtility Study, BRONCUS): a randomised placebo-controlled trial," Lancet, vol. 365, no. 9470, pp. 1552-1560, 2005.

[69] N. Vij, P. Chandramani-Shivalingappa, C. Van Westphal, R. Hole, and M. Bodas, "Cigarette smoke-induced autophagy impairment accelerates lung aging, COPD-emphysema exacerbations and pathogenesis," American Journal of PhysiologyCell Physiology, vol. 314, no. 1, pp. C73-C87, 2018.

[70] N. Vij, "Nano-based rescue of dysfunctional autophagy in chronic obstructive lung diseases," Expert Opinion on Drug Delivery, vol. 14, no. 4, pp. 483-489, 2016.

[71] K. A. Broniowska, A. R. Diers, and N. Hogg, "S-Nitrosoglutathione," Biochimica et Biophysica Acta (BBA) - General Subjects, vol. 1830, no. 5, pp. 3173-3181, 2013.

[72] X. Sun, J. Qiu, S. A. Strong et al., "Discovery of potent and novel S-nitrosoglutathione reductase inhibitors devoid of cytochrome P450 activities," Bioorganic \& Medicinal Chemistry Letters, vol. 21, no. 19, pp. 5849-5853, 2011.

[73] M. Aydin, N. Altintas, L. Cem Mutlu et al., "Asymmetric dimethylarginine contributes to airway nitric oxide deficiency in patients with COPD," Clinical Respiratory Journal, vol. 11, no. 3, pp. 318-327, 2017.

[74] J. X. Feng, Y. Lin, J. Lin et al., "Relationship between fractional exhaled nitric oxide level and efficacy of inhaled corticosteroid in asthma-COPD overlap syndrome patients with different disease severity," Journal of Korean Medical Science, vol. 32, no. 3, pp. 439-447, 2017.

[75] L. Chen, R. P. Patel, X. Teng, C. A. Bosworth, J. R. Lancaster Jr, and S. Matalon, "Mechanisms of cystic fibrosis transmembrane conductance regulator activation by S-nitrosoglutathione," Journal of Biological Chemistry, vol. 281, no. 14, pp. 9190-9199, 2006.

[76] K. Zaman, V. Sawczak, A. Zaidi et al., "Augmentation of CFTR maturation by S-nitrosoglutathione reductase," American Journal of Physiology Lung Cellular and Molecular Physiology, vol. 310, no. 3, pp. L263-L270, 2016.

[77] K. H. Abbott-Banner and C. P. Page, "Dual PDE3/4 and PDE4 inhibitors: novel treatments for COPD and other inflammatory airway diseases," Basic \& Clinical Pharmacology \& Toxicology, vol. 114, no. 5, pp. 365-376, 2014.

[78] M. J. Turner, E. Matthes, A. Billet et al., "The dual phosphodiesterase 3 and 4 inhibitor RPL554 stimulates CFTR and ciliary beating in primary cultures of bronchial epithelia," American 
Journal of Physiology Lung Cellular and Molecular Physiology, vol. 310, no. 1, pp. L59-L70, 2016.

[79] S. I. Rennard, P. M. Calverley, U. M. Goehring, D. Bredenbröker, and F. J. Martinez, "Reduction of exacerbations by the PDE4 inhibitor roflumilast-the importance of defining different subsets of patients with COPD," Respiratory Research, vol. 12, no. 1, p. 18, 2011.

[80] G. M. Solomon, L. Fu, S. M. Rowe, and J. F. Collawn, “The therapeutic potential of CFTR modulators for COPD and other airway diseases," Current Opinion in Pharmacology, vol. 34, pp. 132-139, 2017.

[81] R. S. Pettit and C. Fellner, "CFTR modulators for the treatment of cystic fibrosis," Pharmacy and Therapeutics, vol. 39, no. 7, pp. 500-511, 2014.

[82] G. M. Solomon, S. G. Marshall, B. W. Ramsey, and S. M. Rowe, "Breakthrough therapies: cystic fibrosis (CF) potentiators and correctors," Pediatric Pulmonology, vol. 50, Supplement 40, pp. S3-S13, 2015.

[83] M. N. Bulloch, C. Hanna, and R. Giovane, "Lumacaftor/ivacaftor, a novel agent for the treatment of cystic fibrosis patients who are homozygous for the F580del CFTR mutation," Expert Review of Clinical Pharmacology, vol. 10, no. 10, pp. 10551072, 2017.

[84] F. Van Goor, S. Hadida, P. D. J. Grootenhuis et al., "Rescue of CF airway epithelial cell function in vitro by a CFTR potentiator, VX-770," Proceedings of the National Academy of Sciences of the United States of America, vol. 106, no. 44, pp. 1882518830, 2009.

[85] G. M. Solomon, H. Hathorne, B. Liu et al., "Pilot evaluation of ivacaftor for chronic bronchitis," Lancet Respiratory Medicine, vol. 4, no. 6, pp. e32-e33, 2016.

[86] D. M. Cholon, N. L. Quinney, M. L. Fulcher et al., "Potentiator ivacaftor abrogates pharmacological correction of $\Delta \mathrm{F} 508$ CFTR in cystic fibrosis," Science Translational Medicine, vol. 6, no. 246, article 246ra96, 2014.

[87] X. Wang, B. Liu, X. Searle et al., "Discovery of 4-[(2R,4R)-4(\{[1-(2,2-difluoro-1,3-benzodioxol-5-yl)cyclopropyl $]$ carbonyl\}amino)- 7-(difluoromethoxy)-3,4-dihydro-2H-chromen-2yl]benzoic acid (ABBV/GLPG-2222), a potent cystic fibrosis transmembrane conductance regulator (CFTR) corrector for the treatment of cystic fibrosis," Journal of Medicinal Chemistry, vol. 61, no. 4, pp. 1436-1449, 2018.

[88] M. Gentzsch, H. Y. Ren, S. A. Houck et al., "Restoration of R117H CFTR folding and function in human airway cells through combination treatment with VX-809 and VX-770," American Journal of Physiology. Lung Cellular and Molecular Physiology, vol. 311, no. 3, pp. L550-L559, 2016. 


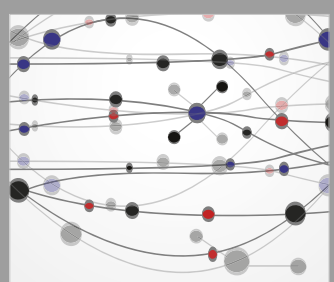

The Scientific World Journal
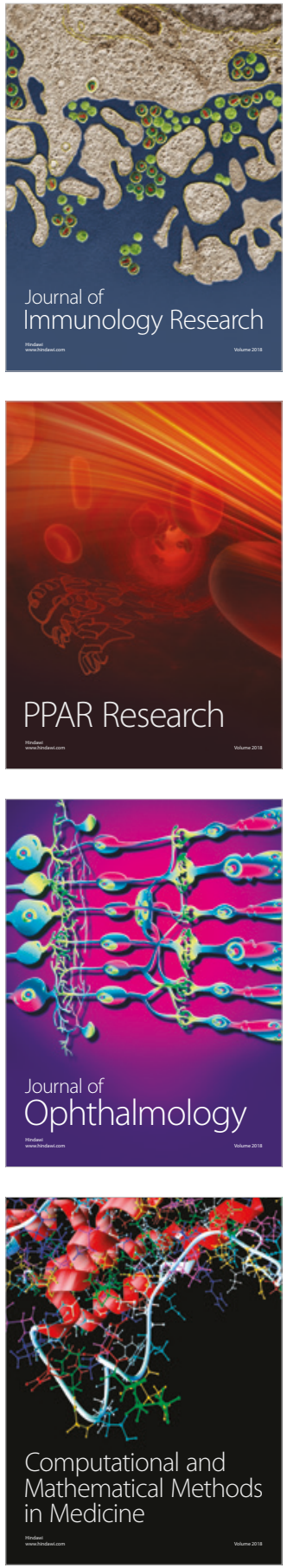

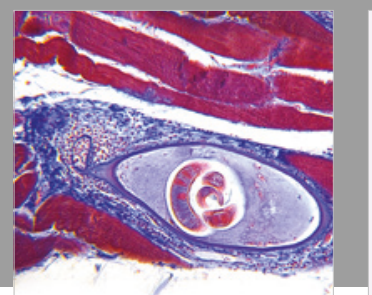

Gastroenterology Research and Practice

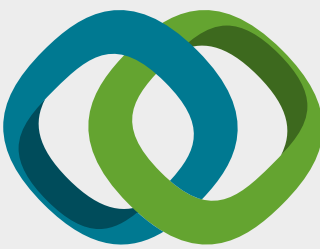

\section{Hindawi}

Submit your manuscripts at

www.hindawi.com
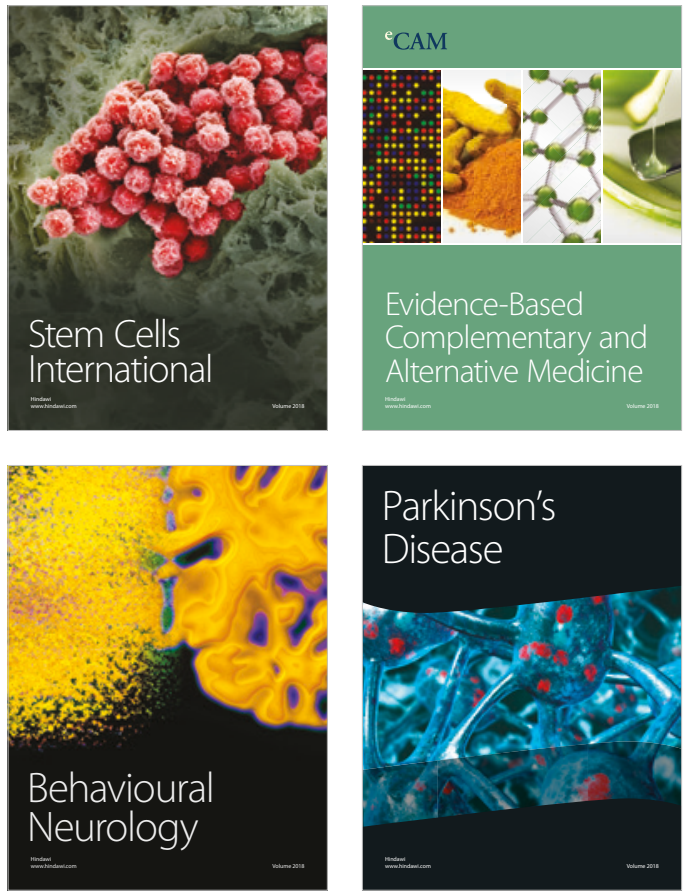

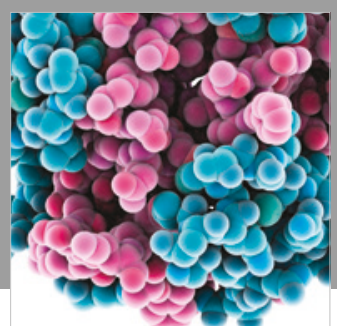

ournal of

Diabetes Research

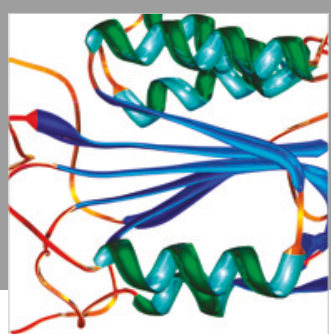

Disease Markers
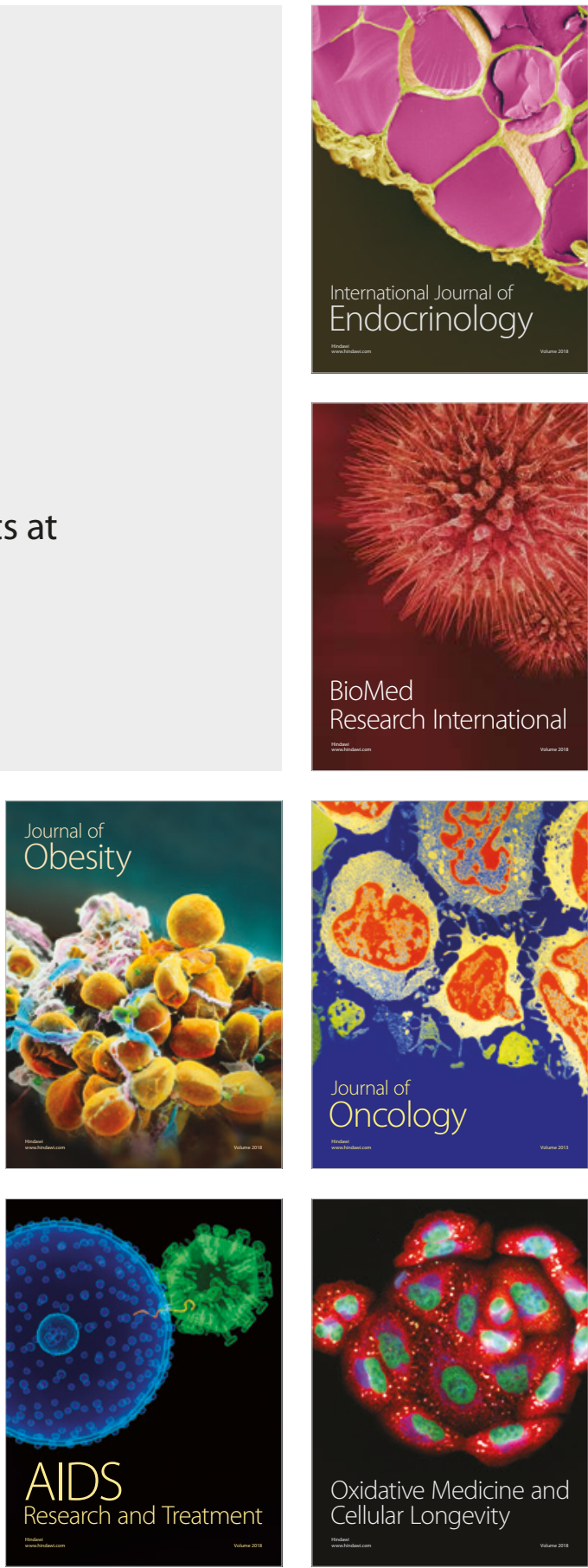